\title{
Research on the Development of Sports Industry and the Training System of Talents in Jilin Province under the Background of New Economy Condition
}

\author{
Yuming Li \\ Baicheng Normal University, Baicheng, Jilin, 137000
}

\begin{abstract}
Knowledge and talent are the main impetus for social progress and national development. In today's world, the competition in the economic, technological, nation defenses and other aspects is the talent competition, so the importance of talent training and urgency in the world today has become a consensus. In order to meet the needs of the socialist modernization drive in the new century, we must strengthen their sense of responsibility and urgency, stand at the height of the times and social development, seize the opportunities, meet challenges and constantly push forward the reform of teaching system and operation mechanism, To meet the requirements of the continuous development of socialist construction. Therefore, in-depth study and study how to cultivate talents has become an important topic facing the society in the new century.
\end{abstract}

Keywords: Physical Industry, Talents Training System, Industry Status

\section{Introduction}

In recent years, the State Council has issued several documents in succession to support the development of the sports industry. In addition to its own market space, demographic dividend and per capita GDP, the outlook for the development of the sports and cultural industry in the next 10 years will be supported by both the government level and the policy level. 
The Policy is to promote the reform of the sports industry deepening. 2010 State Council documents from the macro point of view for the sports industry to deepen reform pointed out the direction; 2011 General Administration of Sport further refinement of the sports industry development and reform of specific targets; 2012 China Football Association reform pilot marks the reform of the "two-track system" In October 2014, the State Council "Opinion" deployment to accelerate the development of sports industry, and promote sports consumption. In the context of the socialist market economy with Chinese characteristics, the role of government and policy is still a decisive factor in industrial development, which determines the scale, speed and structure of sports industry development. These policies, the introduction of the views of the sports industry to promote the development of national will, a clear direction for the future development of the sports industry, but also strengthened the sports industry investor confidence and enhance the confidence of sports consumers.

\section{The Challenges of Chinese Sports Industry}

Effective demand and supply coexist. Insufficient market supply is mainly manifested in the overall small size, low product variety and low quality, which can not meet the rapid growth of demand. From the demand side, it is reflected in blind consumption, showing off consumption and low consumption. The main market is not mature, from the supply side is reflected in terms of slow response to the market and the ability to create demand for weak, small-scale enterprises, the organization is not standardized, backward mode of operation, operating a single product variety, marketing methods and methods obsolete.

These data on the one hand confirmed that China's sports consumption constitutes a single mass consumption and the development of the soil is not fully mature, on the other hand also reflects the lack of supply of sports products and services. Which may result in the growing per capita disposable income, public sports and cultural needs of the expansion, consumer attitudes continue to improve at the same time, facing no place to spend, no money to spend the predicament.

First of all, from the 2008 Olympic Games year, the "sports" was only as a separate expenditure of financial expenditure, had been as a "culture, sports and media," said the Ministry of Finance published the "National Public Finance Expenditure" The proportion of sports expenditure in financial expenditure is only $0.21 \%$ in 2013 , after the peak is only $0.33 \%$, and sports accounted for in the proportion of fiscal expenditure was declining trend; Finally, the composition of the financial expenditure on sports, The mass sports and sports competition with about $9 \%$ of the proportion, but consider the corresponding population base, it is completely unequal. If calculated according to China's 1.3 billion population, per capita expenditure on sports 23 yuan, per capita expenditure on public sports is only 2 yuan. According to the "Fifth National Sports Site Census Data Bulletin" data show that by the end of 2003, China has 850,000 kinds of sports venues, an average of 6.58 per million people have sports venues, the per capita sports space 
area of 1.03 square meters. According to "National Fitness Program (2011-2015)" in 2015, per capita sports space area of 1.5 square meters or more goals, but compared with developed countries, China's per capita sports space area is still less than 1/10 of the United States, Less than 1/12 of Japan. From the million people to maintain the amount of site, the United States, Japan, with an average of more than 200 sports venues per million people, is more than 30 times in China.

\section{Analysis on the Current Situation of Jilin Sports Talents Training Objective}

According to the training direction, the social work of the physical and social needs of the Ministry of Education issued by the social institutions of higher learning undergraduate professional directory and professional introduction requirements: The students mainly learn social sports basic theory and basic knowledge, engaged in social sports Work of basic training, master mass sports activities organization and management, consulting guidance, business development and teaching and research aspects of basic ability. Graduates should have the following knowledge and abilities:

The Forecast of Social Sports Talents Demand in Major Cities of Jilin Province With the development of society, social sports graduates of the overall quality of the students increasingly high demand, but according to the relevant survey shows that different regional demand for talent quality requirements are not the same, the more poor areas of demand for talent is complex Talented people, hoping social sports graduates are all-round, and the needs of the developed areas of social sports professionals is a high-quality specialized talents, I hope the social sports professionals can highlight the expertise, which is cultivated with the training objectives have a certain gap, China's vast territory, the orientation of the training objectives of colleges and universities are not the same. And then the cultivation and development of talent to have a process, and social sports professionals in the cultural foundation is relatively weak, the training cycle is relatively long, and socio-economic development requirements often change faster than the training and development of talent, Side of the requirements there is a certain gap. ${ }^{1}$ In order to gain a better understanding of the current demand of professional sports personnel in Jilin social sports, the author visited such places as provincial and municipal sports bureaus, local fitness centers, various sports associations (clubs), large hotel recreation departments, Community management committee and so on more than 50 may need social sports talents of the employing unit. On the intention of social sports talent demand, professional knowledge, skills and practical ability to carry out a survey, to take home visits, telephone interviews and other investigation. 


\section{Suggestions and Strategies of Sports Personnel Training in Jilin Province}

In Japan, the United States and the United Kingdom almost can not find social sports with China's corresponding professional form of expression of professional settings. This is mainly because foreign countries, especially Western developed countries rarely generalized the professional social sports professional, and generally the social sports professional refinement into a number of professional direction. In order to adapt to the trend of the times, to adapt to the society's new demand for sports talents, it is undoubtedly a wise to draw lessons from the experience of foreign countries to refine the direction of social sports specialty. With the gradual enhancement of national consciousness, the trend of diversification of social sports talents is required. .

An important feature of foreign social sports professional training objectives is "thick foundation, wide caliber, wide adaptation". China's society is accelerating the process of building a well-off, the people continue to enhance awareness of the urgent need for further refinement of social sports talent: a focus on sports management and sports talents, focusing on community sports guidance of sports talent, focusing on leisure and entertainment management Of sports talent and so on. This also requires colleges and universities in the social sports through the guiding ideology of education, in the refinement of professional direction on the basis of the development of new training objectives, is committed to training "thick foundation, wide caliber, wide adaptation" of the new social sports Talent.

Government support and regulation, the scientific planning and management of colleges and universities, teachers and students of the active cooperation and work together to make a new professional can embark on a path of sustainable development essential conditions. This paper puts forward some reference strategies for the emerging problems of the social sports in Jilin University. It is hoped that it will help the social sports profession to embark on the path of healthy development.

It is suggested that the Jilin government should formulate relevant policies and programs, increase the support to the sports industry in Jilin, play a guiding role for the residents' sports consumption in Jilin area, and promote the increase and rationalization of sports consumption, Industry into the healthy development of the road, making the social sports professional living environment can be widened and improved.

To strictly apply the social sports professional institutions of the audit procedures, from the actual needs of talent and future demand situation, its conditions of running schools, teachers, venues and facilities to conduct a rigorous review, blind start or start from the short-term income Act to resolutely put an end to. To social needs as the starting point to set up social sports professional, not tastes big. We should refer to Jilin more than a year after the employment of social sports graduates and the development of Jilin sports industry status and future trends, the professional structure adjustment, and scientific prediction of society in the next few years the demand for social sports 
talent situation, from the overall situation, In the social sports professional employment market is not yet mature and stable conditions to avoid flocking to the sky, always adhere to the students responsible attitude and position.

To clear the sports industry sector is the main social sports professional services. Jilin universities should fully understand the discipline and resource advantages of the university, and on the basis of re-positioning social sports professional, have the choice to cultivate all types of talent, combined with Jilin's industrial structure adjustment, such as Jilin Institute of Physical Education social sports Professional will social sports professional direction is divided into three characteristics of professional direction, namely social sports organization and management, recreation sports, sports tourism, such refinement professional direction is conducive to the formation of professional direction complementary to the new situation.

\section{Conclusion}

The social sports of this emerging profession should be based on social needs as the prerequisite, market-oriented, quality education as the core, the backbone of disciplines as the support to play the overall optimization of education as the guiding ideology, to cultivate "thick foundation, wide Professional talents of social sports ", and clarifies" what kind of social sports talents are needed by the society, what kind of talents will be cultivated ", further reform and perfect the talent cultivation mode of social sports specialty, and build up a more professional talented person of social sports. More scientific and more reasonable curriculum system to train current social needs of social sports talents in Jilin is much meaningful and important.

\section{References}

[1] Wang Jianmin, social sports graduates employment status survey [J]. Journal of Liuzhou Vocational \& Technical College. Journal of Liuzhou Vocational \& Technical College, 2010 (03)

[2] Zhou Jinuo. The new situation of social sports undergraduate reform and development [J]. Journal of Physical Education, 2016 (02)

[3] Wang Dandan, Tan Junhui. Wuhan University social sports professional direction of the investigation and research $[\mathrm{J}]$. Contemporary sports science and technology, 2016 (03)

[4] Ning Wenjing, Fan Hongdi, Zhao Weiming .Social sports professional construction of the problems and countermeasures $[\mathrm{J}]$. Contemporary sports technology, 2014 (36) 